\title{
EHMTI-0309. The management of chronic headache: the current state in the provincial hospital of ouarzazate-city
}

I Hajjaj

From 4th European Headache and Migraine Trust International Congress: EHMTIC 2014

Copenhagen, Denmark. 18-21 September 2014

\section{Introduction}

The province of Ouarzazate is located in the center of the Kingdom of Morocco, a population of over 350,000 inhabitants; it is considered by the Moroccan Ministry of Health as difficult area to provide health human resources.

\section{Aims}

first study of this kind in this city; its aim is to describe the current situation of headaches among the population of Ouarzazate, to recognize the difficulties of health care and offer solutions.

\section{Methods}

it is a retrospective study of over two years (conducted between January 2011 and December 2012), the methodology consisted of analyzing patient files in neurological consultation at Sidi Hssain Benacer hospital. Acute headaches are excluded from this study.

\section{Preliminary results}

headache was the first reason for neurological consultation; it represented $25 \%$ of all causes of consultation. There was a female predominance of $76 \%$. The age of the patients ranged from 3 years to 80 years, with an average age of 37 . Most patients had consulted a general practitioner before seeing a neurologist or were under self-medication. Tension headache was the most frequent type of headache (42\%). Comorbidity with psychiatric disorders was common. Brain CT scan was often requested by general practitioners before addressing the patient to the neurologist.

\section{Conclusions}

To improve the global care of headache, objectives for the short, medium and long term are suggested. Achieving successful results also requires detailed studies and surveys in the region and the involvement of all stakeholders: neurologists and general practitioners, Ministry of Health, the media and civil society.

No conflict of interest.

Published: 18 September 2014

doi:10.1186/1129-2377-15-S1-D26

Cite this article as: Hajjaj: EHMTI-0309. The management of chronic

headache: the current state in the provincial hospital of ouarzazate-city. The Journal of Headache and Pain 2014 15(Suppl 1):D26.
Submit your manuscript to a SpringerOpen ${ }^{\odot}$ journal and benefit from:

- Convenient online submission

- Rigorous peer review

- Immediate publication on acceptance

- Open access: articles freely available online

- High visibility within the field

- Retaining the copyright to your article

Submit your next manuscript at $\gg$ springeropen.com 